dauan a los ydolos e posponían su vida por la salud dela hueste o dela república..." (cap. 24).

Cartagena se interesa especialmente por el uso de los prefijos latinos y explica palabras como veniat y adveniat, gradior, ingredior y egredior. A propósito de esos prefijos lamenta las limitaciones del español: "Nuestro romance non lleua bien estas diferencias" (cap. 33). La misma queja se repite más de una vez. Sin embargo, Cartagena se dió cuenta de que el latín tampoco era perfecto y de que tenía sus lagunas: "Para declarar las diferencias dela reuerencia que se deue alos mayores, la lengua latina pocos vocablos puso e avn ésos non eran suyos, ca delos griegos los tomó" (cap. 18). En cuanto a su conocimiento del griego, nada en esta obra nos indica que supiera más que los términos eclesiásticos corrientes, como dulia, latria, etc.

Northwestern University.

KENNETH R. ScholbERG

Evanston, Illinois.

\title{
UNA CARICATURA DE JUAN RIUIZ DE ALARCÓN
}

Los entremeses del siglo xvir son en su mayor parte pequeños cuadros de costumbres, cómicos y burlescos, sin más pretensiones que la de provocar a risa al público. Sin embargo, en manos del gran maestro del género, Luis Quiñones de Benavente, no pocas veces las "burlas" se mezclan con las "veras", o sea con la sátira social y moral, sátira que nunca llega a ser violenta: "la reprehensión pára en los vicios, sin llegar nunca a las personas", dice don Manuel Antonio de Vargas en el Prólogo a la Iocoseria $^{1}$. Quiñones tenía fama de ser enemigo de toda maledicencia; en un pasaje tradicionalmente interpretado como alabanza al gran entremesista, dice Tirso:

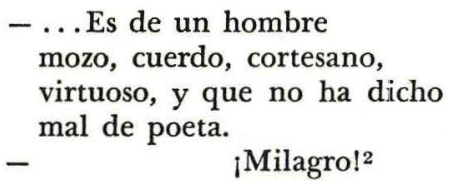

Dada esa fama -enteramente justificada por una lectura de las 142 piezas atribuídas a Quiñones en la Colección de Cotarelo-, nos choca al

1 Iocoseria. Burlas veras, o reprehensión moral y festiua de los desórdenes públicos, en doze entremeses representados y veinte y quatro cantados. Van insertas seis loas y seis Iácaras que los Autores de Comedias han representado y cantado en los teatros desta Corte. Compvestos por Lvis Qviñones De Benauente, natural de la Imperial Toledo. Recopilados por D. Manvel Antonio de Vargas. Dirigidos a D. Mario Mastrillo Beltrán, residente de la Sereníssima Archiduquesa Claudia. Con Privilegio. -En Madrid, por Francisco García, año de 1645. A costa de Manuel López, mercader de libros.

${ }^{2}$ Tanto es lo de más como lo de menos, II, vir. La. fecha de la comedia queda algo dudosa. Cotarelo la cree de 1618-1619 (NBAE, t. 9, p. xxxviii), pero se basa en un dato inexacto; en otro lugar $(N B A E$, t. 17, p. lxxvi) dice: "1620 lo más tarde". Doña BLANCA DE LOS Ríos niega que la alusión sea a Quiñones, y fecha la comedia en 1614 (en su edición de las Obras completas de Tirso, t. 1, Madrid, 1946, pp. 947 ss.). RUTH L. Kennedy, "Studies for the chronology of Tirso's theatre", $H R, 11$ (1943), p. 42, opina que la comedia fué escrita en 1620 y retocada hacia 1623 . 
instante el entremés Los sacristanes Cosquillas y Talegote ${ }^{3}$. Es evidente que el sacristán Cosquillas no es otro que el desdichado Juan Ruiz de Alarcón, satirizado con tanta saña por muchos de sus contemporáneos. En el entremés se nos dice de él que es "muy pequeño, con una corcova atrás y otra delante" (p. 598a). Talegote se dedica a hacer cuantos chistes se le ocurren a propósito de ese defecto (pp. 598-599):

TAL.-No es bueno para amigo, Licenciado.

Cos.-¿Por qué?

Tal.- Porque es de pecho muy doblado.

En la competencia poética que es de rigor en los entremeses en que figuran dos sacristanes (siempre presentados como poetastros ridículos) se vuelve al tema (p. 6ooa):

$$
\begin{aligned}
& \text { Cos.- que también soy poeta. Naya, } \\
& \text { Tal.- } \\
& \text { pues es tu pecho el monte de las Musas. }
\end{aligned}
$$

Dos veces lo apoda de laúd: "Para un laúd ¿no fuera linda caja?" (p. $599 b$ ), "espaldas de tiorba" (ibid.), y dos veces lo compara con animales repugnantes: "señor molde de sapos" (599a), "renacuajo" (6ooa) .

Tampoco se cansa Talegote, que es "muy alto y muy gordo", de echar en cara a Cosquillas su pequeña estatura (598b):

Cos.-Yo quiero a una mujer...

Téngola dada el alma.

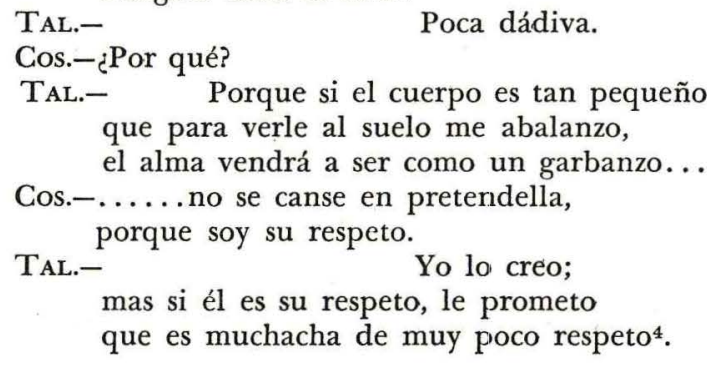

Cuando los interrumpe María, la dama que ambos se disputan, Talegote sigue con su burla (p. 599a-b) :

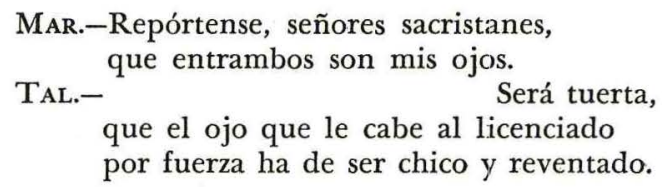

Por supuesto, no hay que pensar que Alarcón fuese el único jorobado en Madrid, ni siquiera el único con dos jorobas, pero si notamos que Cosquillas es además mexicano, la intención del entremés queda perfectamente clara. Cuando María explica que para ganar su amor hará falta

${ }^{3}$ Colección de entremeses, loas, bailes, jácaras y mojigangas desde fines del siglo xvi a mediados del xviii, ed. E. Cotarelo y Mori, NBAE, t. 18, pp. 598-600. infra.

* Este pasaje, en otro contexto, aparece también en el entremés El gabacho. Véase 
algo más concreto que un soneto, Cosquillas se apresura a decir: "Yo te daré del cebo mejicano" (p. 599b). Un momento después, fingiendo en sus versos que María habla con Cosquillas, dice Talegote (p. 6ooa) :

Una niña perlucida, más que gata relamicla, que no como galgo seco, a un amante chichimeco le dijo de aquesta guisa...

Es posible que no tenga mayor importancia el empleo de la palabra "cosquillas" en un pasaje de El subtil cordovés Pedro de Urdemalas de Salas Barbadillo, que se ha creído otra sátira contra Alarcón: "Hubo [en Córdoba] un hombre tan defectuoso que sus partes personales fueron cosquillas de la risa de los más severos" 5 . Lo que no parece casual es que Talegote llame a Cosquillas "señor bola matriz" (p. 599a), empleando la misma frase que fray Juan de Centeno dirigió contra Alarcón: "En el cascarón metido / el señor bola matriz", ni que lo moteje de "baúl de sabandijas" (p. 598b), expresión que nos recuerda el comentario de don Alonso Pérez Marino sobre el gran dramaturgo mexicano: "Baúl-poeta, /semienano o semidiablo"6.

No obstante los insultos recibidos en el curso del entremés, el deforme Cosquillas - como el don Juan de Las paredes oyen- es quien gana al final el amor de la dama.

El entremés Los sacristanes Cosquillas y Talegote se publicó por primera vez en el tomo Navidad y Corpus Christi, que apareció en 1664 en Madrid 7. Según el índice, todos los entremeses fueron "compuestos por Luis de Venavente", y el nombre de este autor figura también a la cabeza de cada entremés. Sin embargo, la autoridad de este tomo deja algo que desear. Las palabras "nunca hasta aora impressos" son falsas, por lo menos en lo tocante a los entremeses: cuatro de ellos ya corrían en letras de molde (uno desde el año 1640); de los cuatro, dos se habían publicado anónimos. Otra pieza volvió a publicarse en 1668, atribuída a Juan Vélez. En todo caso, la Navidad salió unos veinticinco años después de que Quiñones de Benavente (muerto en 1651) había dejado de escribir para el teatro, y era ya muy común la tendencia de atribuirle todos los entremeses habidos y por haber.

El entremés Los sacristanes Cosquillas y Talegote tiene la particularidad de ser uno de los más breves de todos los atribuídos a Quiñones. En los entremeses suyos no incluídos en la Iocoseria el promedio llega a 205 versos; los de la Iocoseria son algo más largos, con un promedio de

5 Citado por Ruth L. Kennedy, "Contemporary satire against Ruiz de Alarcón as lover", $H R, 13$ (1945), p. 149.

${ }^{6}$ Las dos citas apud A. Reyes, "Tres siluetas de Ruiz de Alarcón”, en Capitulos de literatura española, $1^{2}$ serie, México, 1939, pp. 170-171. Ni este artículo ni el mencionado arriba incluyen nuestro entremés entre las sátiras contra Alarcón.

${ }^{7}$ Navidad y Corpus Christi, festejados por los mejores ingenios de España, en diez y seis avtos a lo divino, Diez y seis Loas, y diez y seis Entremeses, representados en esta Corte, y nunca hasta aora impressos. Recogidos por Isidro de Robles. Natural de Madrid. Dedicados al Señor Licenciado Don García de Velasco, Vicario de la Coronada Villa de Madrid, y su Partido. Año 1664. Con licencia. En Madrid, por Ioseph Fernández de Buendía. A costa de Isidro de Robles, Mercader de Libros. 
253 versos $^{8}$. Nuestro entremés, en cambio, consta sólo de 118 versos; fuera del Pistraco, evidentemente incompleto, sólo El marido flemático (que procede de la misma Navidad) es de extensión tan reducida.

Me parece indudable, tanto por la brevedad extraordinaria de la pieza como por su carácter de sátira personal, tan ajeno a Quiñones de Benavente, que Los sacristanes Cosquillas y Talegote no es obra suya ${ }^{9}$. ¿De quién, pues, será? La pregunta no es fácil de contestar. Ruiz de Alarcón tenía muchos enemigos. Lo que sabemos de Tralegote - que era muy alto y gordo- no es base suficiente para identificarlo; en todo caso, es poco probable que el autor del entremés se presentara en escena a sí mismo. Doña Blanca de los Ríos, sin parar mientes en el elemento satírico del entremés, lo ha atribuído a Tirso. Se basa en el hecho ya aludido de que unos versos de este entremés aparecen también en el entremés $E l$ gabacho, impreso como anónimo en la pleiteada Segunda parte de Tirso de Molina; deduce que las dos piezas proceden de la misma mano ${ }^{10}$. El plagio es evidente, pero no lo es tanto la conclusión: Bonilla, que también nota la coincidencia de versos, no vacila en atribuï $E l$ gabacho a Tirso y Los sacristanes... a Quiñones de Benavente, sin fijar la culpa del hurto ${ }^{11}$.

Sean o no del mismo autor, por este camino no puede averiguarse nada, puesto que la atribución de los entremeses incluídos en aquel famoso rompecabezas bibliográfico que es la Segunda parte de Tirso se ha discutido casi tanto como la de sus comedias. Por consiguiente, hasta que no se descubran más datos, el autor de esta caricatura literaria de Ruiz de Alarcón ha de quedar anónimo.

Hannah E. De Bergman

Hunter College, New York.

\section{LA FUENTE DE LAS HOJAS SECAS DE BÉCQUER}

Gustavo Adolfo Bécquer sacó a luz en 1870, en el Almanaque literario del Museo Universal, su esbozo poético titulado Las hojas secas ${ }^{1}$. Esta breve obra, bella y melancólica, consiste en gran parte en un diálogo entre dos hojas secas que, detenidas por un momento, se cuentan sus recuerdos de otros días, cuando, besadas por el sol, se mecían alegres en el aire, reflejadas en las aguas transparentes del río; había insectos breves.

${ }^{8}$ No nos referimos aquí a los entremeses cantados o bailes, que suelen ser más

- En un tiempo creí ver otro inconveniente para la atribución de este entremés a Quiñones en la alabanza que del entremesista hace Alarcón en La culpa busca la pena (II, VII): "La comedia, felizmente, / aplaudida al puerto llega, / que era de Lope de Vega, / y el baile, de Benavente". Sin embargo, en un estudio reciente sobre esa comedia (NRFH, 7, 1953, p. 447), Courtney Bruerton llega a la conclusión de que estos versos, los únicos en el teatro de Alarcón en que se alude por sus nombres a poetas contemporáneos, fueron añadidos por otra mano que la del poeta mexicano.

${ }_{10}$ Op. cit., pp. $969-97^{\circ}$

11 "Entremeses del siglo xvir atribuídos al Maestro Tirso de Molina", ed. El Bachiller Mantuano, en Ateneo, 7 (1909), p. 74, nota.

1 Cf. Franz Schneider, "Tablas cronológicas de las obras de Gustavo Adolfo Bécquer", RFE, 16 (1929), p. 394. 